\title{
Amino acids and biogenic amines determination in Mystus nemurus.
}

\begin{abstract}
The concentration of biogenic amines, i.e., histamine, putrescine, and cadaverine were studied as indicators of Mystus nemurus muscle quality under different storage conditions, namely, ambient $(28 \pm 2 \mathrm{C})$, chilled $(10 \pm 2 \mathrm{C})$ and in iced $(2 \pm 1 \mathrm{C})$ temperature. The biogenic amine contents were found to correlate with the free amino acids contents. The level of biogenic amines increased in accordance with decreasing free amino acids during storage $(\mathrm{P}<0.05)$. The cadaverine level reached a peak, $186.24 \mathrm{mg} / \mathrm{g}$, after $24 \mathrm{~h}$ at ambient temperature, $371.98 \mathrm{mg} / \mathrm{g}$ after 10 days at $10 \mathrm{C}$, and $385.49 \mathrm{mg} / \mathrm{g}$ after 20 days at iced temperature. Unacceptable levels were reached after $12 \mathrm{~h}$ at ambient, 8 days at $10 \mathrm{C}$ and 16 days at $2 \mathrm{C}$. Putrescine increased at a slower rate than histamine and cadaverine. The present study demonstrated the potential of cadaverine production as a quality indicator of $\mathrm{M}$. nemurus during storage.
\end{abstract}

Keyword: Amino acids; Biogenic amines; Mystus nemurus. 